\title{
OUTCOMES AND MANAGEMENT OF INFANTS BORN WITH CONGENITAL DIAPHRAGMATIC HERNIA: A RETROSPECTIVE STUDY IN A TERTIARY NEONATAL UNIT
}

\author{
Tom Newman - Final Year Student Doctor, University of Cambridge (tn292@cam.ac.uk) \\ Mercy Weidenmuller - Clinical School, University of Cambridge \\ Dr Yogen Singh - Consultant Neonatologist with Expertise in Cardiology, Cambridge University \\ Hospitals
}

Background

- Congenital diaphragmatic hernia (CDH) occurs in approximately $3 / 10,000$ lives births ${ }^{1}$

- Clinically presents with respiratory distress and acute pulmonary hypertension (Figure 1)

- Mortality rates of $20-30 \%$ are reported in isolated $\mathrm{CDH}$ and $>50 \%$ when associated with other defects ${ }^{1,2}$

Aims

- Compare outcomes of infants with $\mathrm{CDH}$ treated at Cambridge University Hospitals (CUH) with published data

- Review cardiorespiratory management strategies used at CUH with available electronic patient records

\section{Methods}

- Retrospective review of discharge summaries and available e-records for all infants with $\mathrm{CDH}$ treated at our institute between Jan 2007-Dec 2016

\section{Results}

- 52 infants with $\mathrm{CDH}$ were treated at $\mathrm{CUH}$ during the study period, overall mortality rate $21 \%$

- Mortality was higher in those born with concomitant cardiovascular malformation (CCM), although it was not statistically significant ( $p=0.19$ Fisher's Exact Test)

- Additional specialist services were required significantly more frequently in those born with heart defects (Figure 2) ( $p=0.0017$ Fisher's Exact Test)

- In 12 of the 52 cases, electronic patient records were available

- Mortality rates in this subgroup were comparable to the whole cohort ( $25 \%$ vs $21 \%$ )

- On review of management an aggressive strategy to diagnose and treat pulmonary hypertension was used (Figure 3)

\section{Conclusions}

- Outcomes in our cohort appear in line with the best published for both isolated $\mathrm{CDH}$ and cases associated with CCM

- Management focussing on pulmonary hypertension may therefore be beneficial and this approach is supported by the CDH EURO Consensus guidelines ${ }^{3}$
Figure 1: Pathophysiology of CDH

$$
\text { Pulmonary Hypoplasia and Compression }
$$

Respiratory Distress

Pulmonary Hypertension

Cardiorespiratory Failure

Table 1: Outcomes of infants with $\mathrm{CDH}$

\begin{tabular}{c|c|c}
$\begin{array}{c}\text { Type of } \\
\text { Pathology }\end{array}$ & $\begin{array}{c}\text { Neonatal } \\
\text { Mortality }\end{array}$ & $\begin{array}{c}\text { Transfer for } \\
\text { specialist services } \\
\text { (e.g. ECMO) }\end{array}$ \\
\hline Isolated CDH & $7 / 42(16.7 \%)$ & $2 / 42$ (0 deaths) \\
$(4.8 \%)$
\end{tabular}

Figure 2: Comparative outcomes between isolated CDH and $\mathrm{CDH}$ associated with cardiovascular malformation (+CCM)

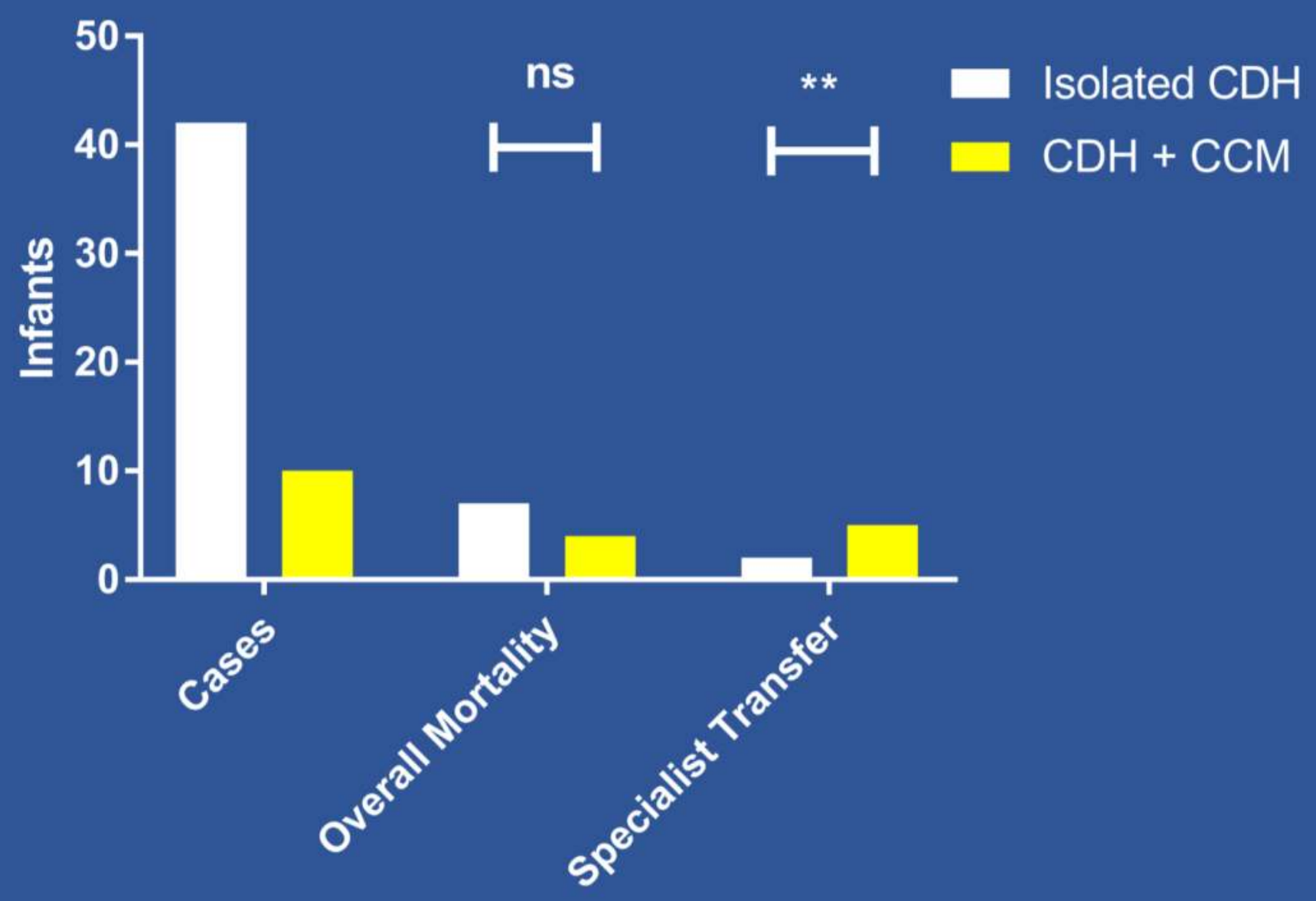

Figure 3: Cardiorespiratory management of CDH ( $n=12$ )

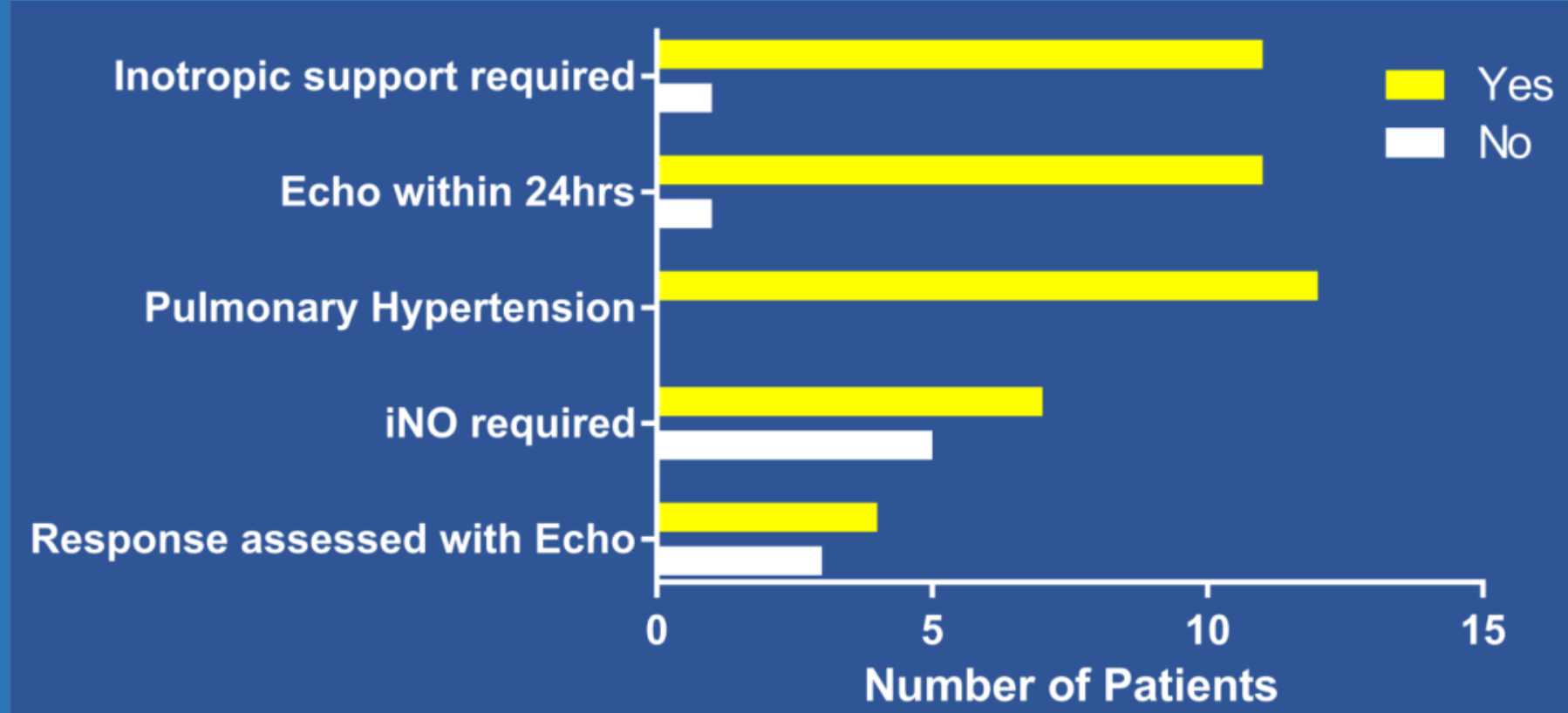

References

8

UNIVERSITY OF CAMBRIDGE School of Clinical Medicine
1. McGivern MR et al. Arch Dis Child Fetal Neonatal Ed. 2015

2. Bojanić K et al. J Pediatr Surg. 2015

3. Snoek KG et al. Neonatology. 2016 Copyright of the authors
Cambridge University

Hospitals

NHS Foundation Trust 